\title{
DESCARTE DE RECÉM-NASCIDOS COM DEFORMIDADES: RELENDO FONTES PRIMÁRIAS*
}

\author{
DISPOSE OF NEWBORNS WITH DEFORMITY: \\ REVIEW OF PRIMARY SOURCES
}

\author{
Dalva Maria de AImeida MARCHESE ${ }^{1}$
}

\begin{abstract}
RESUMO
As citações de exemplos históricos nos inícios de textos das mais diversas áreas do saber são uma constante que parecem não refletir consulta igualmente numerosa às fontes primárias, mas sim uma concordância tácita, independente de se avaliar a intenção do autor. A necessidade da releitura e da discussão dos textos clássicos se fez a partir da preocupação com a prática do descarte de bebês nascidos com deformidades, tida como generalizada na Grécia antiga, a partir de citações em textos os mais diversos. Os fatos conhecidos através dos textos e sua contextualização possível levam à conclusão que não há documentação histórica que comprove essa prática como generalizada na Grécia antiga.
\end{abstract}

Palavras-chave: deformidade, anomalia congênita, deficiência, recémnascido, bioética.

\begin{abstract}
The citations of historical examples in the beginnings of texts of the most several areas of the knowledge are a constant that seems not to reflect consultation equally numerous to the primary sources, but yes a tacit agreement, independent of evaluating the author's intention. The need of the review and of the discussion of the classic texts it was made its starting
\end{abstract}

(*) Texto de preparação da dissertação "O nascimento do cidadão diferente: prognóstico ou julgamento", apresentada em março de 2002 para obtenção do grau de Mestre, sob orientação do Dr. Geraldo A. Fiamenghi, com apoio da UNISA - Universidade de Santo Amaro.

(1) Mestra em Distúrbios do Desenvolvimento da Universidade Presbiteriana Mackenzie, fisioterapeuta supervisora de estágio de Fisioterapia Aplicada à Pediatria no H. G. do Grajaú, professora na cadeira de Pediatria e responsáve pelo Ambulatório de Atendimento Fisoterapêutico e Estudos Multidisciplinares de Genética Humana - Projeto Curumim, da Fac. de Fisioterapia da UNISA.

Endereço para correspondência: Rua Tarquínio de Souza, 272 - 02434-040 - São Paulo - SP

Fone: 11-6236-2096/ 11-9122-3856 - e-mail: ftadalvamarchese@uol.com.br 


\begin{abstract}
from the concern with the practice of the disposed of babies born with deformities, had as having generalized in ancient Greece, starting from citations in texts the most several. The well-known facts through the texts and its possible context, take to the conclusion that there is not historical documentation that checks that practice as having generalized in ancient Greece.
\end{abstract}

Keywords: deformity, congenital anomalies, disable, newborn, Bioethic.

Afirmar que as atitudes e os conceitos atuais se formaram como parte da história da humanidade e que a sua compreensão e discussão não podem prescindir das informações sobre seu passado histórico, não causa discordância. Quando o assunto de interesse é uma parcela da população humana, com necessidades tão especiais como os recém-nascidos com anomalias congênitas, é indispensável relembrar a história de alguns dos que desde muito tempo se ocupam do tema, a favor ou contra o direito de uma vida digna para esses cidadãos, muitas vezes em um mesmo período de tempo; é relembrar fatos que ajudem a melhor observação dos acontecimentos dos dias de hoje. As constantes citações, no entanto, não parecem refletir consulta igualmente numerosa às fontes primárias, mas sim uma concordância tácita que pode fazê-las servir a qualquer fim, como se fossem um adereço, um item obrigatório, um segmento a mais no texto, independente de se avaliar a intenção do autor. Daí a necessidade da releitura e da discussão que busque o conhecimento dos fatos e sua contextualização possível.

A referência à Grécia Antiga é usual nas mais diversas obras. Assim também nos assuntos que remetem à área da saúde, mormente quanto ao perfeito, ao saudável, ao fisicamente adequado e mesmo quanto ao física ou mentalmente deficiente, a citação sempre aparece. Em Pessotti (1984) lê-se:

"De todo modo, é sabido que em Esparta crianças portadoras de deficiências físicas ou mentais eram consideradas sub-humanas, o que legitimava sua eliminação ou abandono, prática perfeitamente coerente com os ideais atléticos e clássicos, além de classistas, que serviam de base à organização sócio-cultural de Esparta e da Magna Grécia" (Pessotti, 1984, p. 3).

A mesma questão é referida em História da Antigüidade, por Michulin (s/d), quando descreve o sistema educativo dos espartanos e o cuidado com sua prole, avaliada em seu vigor físico pelos anciãos que decidiriam sobre sua sobrevivência. Em Assumpção Jr. (2000), há uma citação de 'A República', de Platão, em que o filósofo descreve que Esculápio não prolongava a vida dos "corpos de constituição doentia... que os poriam em condições de se reproduzirem em outros seres fadados, certamente a serem iguais aos progenitores" (p. 2).

Porém, é outra a visão se buscarmos esclarecer o contexto cultural do período de existência das pessoas, neste caso, das crianças com deformidade nascidas na Grécia Antiga e que comumente aceitamos terem sido impedidas de sobreviver, fossem espartanas ou atenienses. Essa foi a preocupação de Edwards (1996), no estudo sobre normalidade e eugenia, em artigo que se baseou nos cinco textos gregos que compõem as fontes primárias sobre o tema, apoiada nos escritos de Patterson (1985, apud Edwards, 1996), que discute justamente a necessidade dessa contextualização, e nos escritos de Garland (1995, apud Edwards, 1996), o qual afirma que nem todas as crianças devem ter sido destruídas e que as recomendações de 
Platão e Aristóteles sugerem a existência de prática oposta.

Segundo a autora, o vocabulário encontrado nos textos clássicos é vago e, muitas vezes, impossibilita saber exatamente o que se apresenta. Por exemplo, Platão descrevia o nascido doente e o disforme sem precisar um e outro; Aristóteles, assim como Platão, usava 'mutilou' para significar diferiu do padrão e 'deformidade' quando falava da calvície; fez também uma especulação, de que a fêmea seria um macho tecnicamente deformado; Soranus usava 'tamanho e forma apropriados' mas não descrevia o que, afinal, isso significava (Edwards, 1996).

Quanto à interpretação das fontes, a historiadora lembra que $A$ República, de Platão é situação ideal, preparada para o desenvolvimento do estudo dos filósofos e não um texto histórico, o que se confirma no Livro II de A República, quando Adimanto propõe a Sócrates imaginarem um Estado em processo de criação e observar nele o desenvolvimento da justiça e da injustiça, obtendo imediata aceitação de sua proposta; é sobre esse Estado ideal que o texto se desenvolve. No Livro $V$ de $A$ República, discutindo sobre as questões da família e da prole nesse mesmo Estado ideal, Platão descreve um diálogo entre Glaucon e Sócrates:

"O que fazer com as crianças ...

- E destarte, encarregando-se das crianças que forem nascendo os organismos instituídos para esse fim, os quais podem ser compostos de homens, de mulheres ou de pessoas de ambos os sexos, pois também os cargos públicos serão acessíveis tanto às mulheres como aos homens... [Sócrates]

- Sim.

- Essas autoridades, digo, tomarão os filhos dos melhores e os levarão para o infantário, num bairro especial da cidade, onde os deixarão a cuidado das amas-de-leite; quanto aos filhos dos seres inferiores - e da mesma forma se dentre os primeiros nascer algum aleijado - os esconderão, como convém, num lugar secreto e oculto.

- Sim - disse Glaucon - se quisermos que a raça dos guardiães se conserve pura" (Platão, p. 111-2).

Respondendo à obra de Platão, Aristóteles escreve Política, colocando-se a tarefa de escolher dentre as sociedades políticas aquela na qual os homens pudessem viver de acordo com sua vontade. Estabelece, então, princípios básicos para seu estudo, afirmando-se contra $A$ República e as propostas de Platão de que, segundo Aristóteles, os filhos, as mulheres e os bens fossem comuns.

É em Política que encontramos a frase de Aristóteles, que dá nome ao texto de Edwards (1996); no livro quarto, capítulo XIV, no qual o filósofo se dedica ao estudo das "Regras a respeito do casamento", lê-se:

“§ 10. Com respeito a conhecer quais os filhos que devem ser abandonados ou educados, precisa existir uma lei que proíba nutrir toda criança deforme." (Aristóteles, p. 150) - grifo acrescentado.

No Teeteto, Platão descreve o diálogo entre Sócrates e Teeteto, instado por seu mestre a responder em que consiste o conhecimento. Para encorajá-lo a responder, Sócrates conta-lhe que é filho de parteira; mas como homem, não pode exercer tal função; porém, exerce a arte obstétrica acompanhando homens no parir de suas idéias, acompanhando suas almas ao invés de seus corpos, e conclui:

"...Se te expus tudo isso, meu caro Teeteto, com tantas minúcias, foi por suspeitar que algo em tua alma está no ponto de vir à luz, como tu mesmo desconfias. Entrega-te, pois, a mim, como a filho de uma parteira que também é parteiro, e quando eu te formular alguma questão, procura responder a ela do 
melhor modo possível. E se no exame de alguma coisa que disseres, depois de eu verificar que não se trata de um produto legítimo mas de algum fantasma sem consistência, que logo arrancarei e jogarei fora, não te aborreças como fazem as mulheres com seu primeiro filho. (151b-c) (Aristóteles, p. 14).

Ao final da discussão, Sócrates se remete-se mais uma vez ao tema:

...E ainda estaremos, amigo, em estado de gravidez e com dores de parto a respeito do conhecimento, ou já se deu a expulsão de tudo?

Teeteto - Sim, por Zeus! Com a tua ajuda, disse mais coisas do que havia em mim.

Sócrates - E não declarou nossa arte maiêutica que tudo isso não passa de vento que não merece ser criado?" (210B) (Aristóteles, p. 98).

O quarto texto das fontes primárias, de Plutarco (50 a 120 d.C.), foi escrito em Roma, na época do imperador Trajano (98 a 117 d.C.), e contava as glórias de Esparta sob Licurgo, séculos antes; é o texto a que se refere Michulin (s/d), também citado por Edwards (1996):

"O progenitor não gozava do pleno direito de criar o filho; tomava-o e levava-o a certo local denominado lesque: os mais velhos da tribo, ali sentados, examinavam a criança; se bem constituída e robusta, mandavam que a criasse e atribuíam-Ihe um dos nove mil lotes; se mal nascida e deforme, remetiam-na para um sítio chamado Apótetas, uma espécie de precipício no Taigeto: quem não tem desde o princípio uma natureza apta para a saúde e vigor, pensavam, é melhor para ele e para a cidade que não viva. Por isso as mulheres não banhavam os recém-nascidos em água, mas em vinho, como toque de sua constituição. Dizem, com efeito, que, ao contato com o vinho puro, as crianças epiléticas e doentias morrem entre convulsões, ao passo que as sadias ficam ainda mais bem temperadas e sua compleição se robustece." (Plutarco, p. 27).

A obra de Plutarco que contém o trecho citado é descrita por Santos (1970), como "menos histórica do que moral" (p. 110), uma vez que foi escrita para servir como exemplo de virtudes cívicas para os jovens romanos; "Vidas Paralelas" compõe-se de uma série de biografias em que vultos romanos e gregos se alternam, tendo suas ações analisadas e submetidas a julgamento comparativo.

O último texto analisado por Edwards (1996) é o manual para parteiras de Soranus, de cuja aplicação pouco se sabe, segundo a autora, e que orientava sobre a avaliação do bebê ao nascer. O exemplar consultado para a estruturação deste texto encontra-se na biblioteca de uma faculdade de Filosofia e, desde sua compra, jamais havia saído da prateleira.

De acordo com Burguière, Gourevitch e Malinas (1990), Soranus nasceu, provavelmente, em Éfesos, na Ásia Menor, em meados do primeiro século da era cristã; não há registros escritos sobre sua bibliografia, tarefa à qual ele também não se dedicou em nenhuma de suas obras. Sua formação médica se deu na escola de Alexandria, o que explicaria seu vasto conhecimento sobre anatomia. Ao lado da escola de Alexandria que primava pelo estudo da anatomia, coexistiam a medicina hipocrática, clínica e humoral, e a medicina romana da época imperial, enciclopédica. Soranus exerceu medicina em Roma durante os impérios de Trajano (98-117 d.C.) e Adriano (117-138 d. C.), tendo falecido aproximadamente em 129 d. C.. Seguia a orientação metodista da Medicina, fundamentada na preocupação com a sistematização dos procedimentos. Escreveu aproximadamente 20 tratados sobre medicina interna, clínica e 
cirurgia, dentre eles um dedicado ao serviço das parteiras, que hoje conhecemos como Ginecologia e Obstetrícia.

O texto original escrito em grego, a língua oficial da Medicina Imperial Romana, preservouse, e uma de suas traduções mais recentes é a de Burguière, Gourevitch e Malinas, com o primeiro tomo editado em 1988, em francês. Dentro desse imenso tratado, que cuida desde questões anatômicas da genitália feminina até assuntos como aborto, sempre com preocupação descritiva e buscando sistematizar o trabalho da parteira, num trecho, que traduzido para o francês resultou em aproximadamente 300 palavras, Soranus descreve um protocolo a ser seguido no momento do nascimento para avaliação da vitalidade dos bebês.

Nas maternidades atuais temos protocolos que, guardadas as devidas proporções, são os mesmos. As diferenças resultam das técnicas que hoje dominamos e que nos permitem, por exemplo, manter vivos prematuros de menos de sete meses de gestação, os quais Soranus, com toda a razão, afirmava que não sobreviveriam.

Mas o mais interessante do texto é a questão exposta por Iceton (2001), estudante de Medicina da Universidade de Calgary, analisando o trecho de Soranus e comparandoo ao de Virgínia Apgar: dezenove séculos depois, ambos orientam a observação de tono muscular, irritabilidade reflexa e esforço respiratório. Porém, a conclusão de Iceton, (2001) de que o boletim de Apgar serve como prognóstico para salvar vidas e o de Soranus para avaliar o recém-nascido que deve ser aceito ou rejeitado, parece apressada: trata-se de um manual, como tantos usados na área da saúde.

Certamente é por esse mesmo motivo, por se tratar de um texto exclusivamente de orientação de rotina obstétrica, sem preocupações com avaliações de qualquer ordem, que Edwards (1996) considera sua descrição insuficiente: não é um tratado de neonatologia ou pediatria, com a preocupação de descrever a criança; e a mesma razão pode ter induzido Burguière, Gourevitch e Malinas (1990), em suas notas, a classificar a não descrição completa do destino da criança como uma atitude pudica de Soranus. Se havia ou não o descarte, isso não está afirmado no texto; o que ele afirma é que a avaliação inicial indica se o bebê é naturalmente apto a sobreviver por si só, como no Boletim de Apgar, não se reportando ao destino do bebê nos casos em contrário.

Sem qualquer técnica mais avançada, com critérios de assepsia algumas vezes duvidosos, contando apenas com sua experiência e ajuda de seus deuses, é de pensar como seriam os partos das mães gregas e romanas... e de sua semelhança com os partos que ocorrem ainda hoje neste país, em cada rincão de miséria onde a solidariedade e as mãos da parteira são os únicos recursos com que os novos cidadãos contam. Duas realidades tão distantes, coexistindo, por permissividade dos viventes: as maternidades chamadas de primeira linha, ou "top de linha", com todos os recursos que a técnica oferece, e o parto domiciliar, realizado pela parteira, pela vizinha, por quem estiver por perto, pelo bombeiro, quando a sorte bafeja.

Portanto, reafirmando Edwards (1996), as conclusões sobre o descarte de bebês são sempre sobre suposições anacrônicas e há carência de evidências documentais para se afirmar que a prática era corrente no mundo greco-romano. Além disso, há que se acrescentar que nessa época não havia suficiente clareza a respeito da etiologia das anomalias congênitas; havia o registro da ocorrência e a observação, por exemplo, da repetição da deformidade que podia ocorrer algumas vezes na descendência. Darwin fez editar A Origem da Espécies, em 1859; e A Descendência do Homem, em 1871; Mendel deu a conhecer seus estudos em 1865; no mesmo período em que Galton, o primo de Darwin e criador da Eugenia, fazia editar seus 
trabalhos. Os estudos sobre a herança em humanos que formaram a base do conhecimento de nossos dias foram realizados por homens que viveram no século XIX; os efeitos de suas teorias, a favor ou contra a Humanidade, fizeram-se sentir a partir da metade do século XIX (Tort, 2000).

No mundo desenvolvido, usa-se a ultrasonografia, a amniocentese e outras refinadas técnicas de diagnóstico pré-natal. No mundo antigo, o parto não era uma situação médica e a saúde, ou doença, dos bebês e crianças não era de interesse médico; assim, um bebê com deformidade não era visto necessariamente como inferior, sem atrativos ou necessitando de cuidados médicos, o que veio a ocorrer a partir dos séculos XIX e XX, com seus valores culturais e médicos. A obstetrícia somente apareceu como parte dos cuidados médicos entre 1600 e 1700; a neonatologia iniciou sua organização, em 1949, apesar de seu primeiro manual, The Nursing, escrito por Pierre Budin, ser de 1900. Equipamentos básicos nos berçários de hoje, as primeiras incubadoras foram construídas em 1835, somente aparecendo na literatura ocidental em 1857 (Duncan, 2000).

Os padrões de normalidade do corpo humano surgiram nos tempos modernos, com o desenvolvimento da estatística e da eugenia, com os bimétricos, seguidores de Galton (Tort, 2000). Edwards (1996) considera então que havia um corpo humano ideal, compendiado no estatuário grego; mas era idéia diferente da perfeição atingível que caracteriza o pensamento moderno.

E, assim, mesmo que todos os bebês com anomalias congênitas imediatamente identificáveis tivessem sido destruídos, as condições de manifestação tardia, que somente com a idade se tornariam perceptíveis, e as anomalias adquiridas por doenças ou traumas seriam suficientes para povoar o mundo antigo de pessoas com deformidades e deficiências diversas. Edwards (1996) lembra ainda que, certamente, a população da Grécia
Antiga devia ter muito pouco a ver com o ideal do modelo Neoclássico Grego, com corpos humanos matematicamente perfeitos.

Por acaso, ou decisão, bebês com anomalias sobreviveram; existem relatos da antigüidade de alfaiates, mascates, escravos, trabalhadores de metais e minérios, e mesmo soldados, com deficiências físicas diversas, confirmando que um impedimento físico não constitui, por si só, dependência econômica; se bem que vale lembrar que a equação que relaciona deformidade física e dependência econômica é uma abstração moderna. Se, por um lado, não há sugestões de que bebês tenham sido destruídos exclusivamente em consequência de sua deformidade, por outro, há considerações práticas sobre o cuidado de recém-nascidos com deformidades.

Como deformidade não pode ser considerada uma categoria absoluta, é possível que crianças com deformidade tenham sido descartadas por fatores como excesso de crianças, criança do sexo feminino e não primogênita, criança ilegítima. Certamente, uma menina, mesmo não sendo obrigatoriamente indesejada, se deformada seria especialmente indesejada.

A conclusão do estudo de Edwards (1996) é que a documentação especificamente sobre o tema da descendência com deformidades é escassa para que se afirme ter sido a destruição dessa descendência uma prática comum. A atmosfera cultural na qual os bebês gregos antigos nasciam não julgava pessoas deformadas como más, desprezíveis ou doentes. E as suposições modernas sobre custo econômico, atrativos estéticos, padrões de saúde médica não são instrumentos adequados para avaliar essas crianças na Grécia Antiga.

Hoje, a documentação é farta. No futuro, não será difícil fazer a avaliação de nossa postura diante da criança nascida com qualquer tipo de condição considerada como inaptidão para a sobrevivência, seja essa condição física, mental, genética, econômica 
ou política. Os instrumentos teóricos e técnicos que criamos ou refinamos continuam tendo sua utilização sujeita aos desígnios daqueles que os utilizam. A fraternidade, a filantropia, a solidariedade, o altruísmo continuam existindo. E a Humanidade continua distribuída a favor ou contra as diversas questões; os códigos de direitos especiais, a Bioética são a tentativa de balizar essas diferenças, reduzindo a distância que se abriu entre a ética e o conhecimento. Se a história não foi escrita, não se pode garantir que não havia na antigüidade grega quem se dedicasse a cuidar do cidadão com necessidades especiais, livrando-o de um julgamento inicial e definitivo.

\section{REFERÊNCIAS BIBLIOGRÁFICAS}

ARISTÓTELES (384-322 a.C.). Política. Tradução de Torrieri Guimarães (2001). São Paulo, Martim Claret.

ASSUMPÇÃO Jr., F. B. \& Sproveri, M. H. (2000). Introdução ao estudo da deficiência mental. São Paulo, Memnon.

DUNCAN, R. (2000). History, Ethics, and Outcomes. CSM Pediatrics. Disponível: http://neonatology.org/syllabus/ nheo.web.pdf. (consultado18.11.2001).

EDWARDS, M. L. (1996). The cultural context of deformity in the ancient greek world: "Let there be a law that no deformed child shall be rearead". The Ancient History Bulletin, 10(3-4):79-92. Disponível: http://ivory.trentu. ca/www/cl/ahb/ahb10/ahb-10-3-4ahtlm (consultado:05.05.2001).

ICETON, S. (2001). The Soranus score. JAMC, 164(5):674.

MICHULIN, A. V. (s/d). História da antigüidade. Lisboa, Centro do Livro Brasileiro.

PESSOTTI, I. (1984). Deficiência mental: da superstição à ciência. São Paulo, EDUSP.

PLATÃO (427-347 a.C.). Diálogos III - A República. Tradução de Leonel Vallandro. Rio de Janeiro, Ediouro.

PLATÃO (427-347 a. C.). Diálogos: Teeteto e Crátilo. Tradução de Carlos Alberto Nunes (1988). $2^{a}$ ed., Belém, UFPA.

PLUTARCO (46-120 d.C.). Vidas Paralelas. Tradução de Jaime Bruna (s/d). São Paulo, Cultrix.

SANTOS, T. M. (1970). Noções de história da educação. 13ª ed., São Paulo, Cia. Editora Nacional.

SORANUS (50?-129 d.C.). Soranos D'Éphèse - Maladies des femmes. Tradução de Paul Burguère, Danielle Gourevitch e Yves Malinas (1988 - vol. I; 1990 - vol. II). Paris, Les Belles Lettres.

TORT, P. (2000). Darwin lido e aprovado. Crítica Marxista. São Paulo, 11:109-21. 
